\title{
OVERCURRENT RELAY COORDINATION EFFECTS ON RELIABILITY INDICES
}

\author{
K. Mazlumi ${ }^{1}$ and H. Askarian Abyaneh ${ }^{2}$ \\ ${ }^{1,2}$ Department of Electrical Engineering \\ Amirkabir University of Technology, Iran \\ ${ }^{1}$ kmazlumi@aut.ac.ir, ${ }^{2}$ askarian@aut.ac.ir
}

\begin{abstract}
Protection system failures are the main causes of cascading outages. There is a need to evaluate reliability indices, yet the effects of relay coordination methods have not yet been investigated in the existing literature. In this paper, an algorithm based on sequential Monte Carlo simulation is proposed to find the reliability indices for different overcurrent relay coordination methods. The proposed algorithm is applied to the results of three different relay coordination methods of a sample network. Then the reliability indices for the results of three different relay coordination methods are compared, and it is shown how the reliability indices are affected by the results of relay coordination methods.
\end{abstract}

\section{OPSOMMING}

Mislukkings van beveiligingstelsels is hoofsaaklik verantwoordelik vir kaskadeonderbrekings van elektriese netwerke. Derhalwe is dit noodsaaklik dat betroubaarheidsindekse geevaleer moet word teen die agtergrond dat min aandag gegee word aan relêkoördinasie. Monte-Carlo simulasie word voorgehou as oplossing van die koördinasievraagstuk. Die voorgestelde algoritme word toegepas op die afsonderlike koördinasiemetodes van 'n denkbeeldige network. Die resultate van die ondersoek toon dat die berekende betroubaarheidsindeks afhang van hoe koördinasiemetodes toegepas word.

\footnotetext{
${ }^{1}$ The author was enrolled for a PhD degree in the Department of Electrical Engineering, Amirkabir University of Technology
} 


\section{INTRODUCTION}

Directional overcurrent relays are widely used for the protection of radial and ring sub-transmission systems as an economical protection system [1, 2]. Directional overcurrent relays are mainly used for the primary protection of ring subtransmission systems [3]. The most vital task when installing directional relays on a system is selecting suitable settings such that their fundamental protective function is met under the requirements of sensitivity, selectivity, reliability, and speed [4]. Several methods are proposed for the coordination of overcurrent relays $[2,4,5,6$, 7].

Protection systems play a vital role in maintaining the high degree of service reliability required in present day power systems [8]. A study by the North American Electric Reliability Council (NERC) shows that protective relays are involved in about 75 percent of major disturbances [9]. It has been observed that hidden failures of protection systems commonly lead to multiple or cascading outages. Overcurrent relay mis-coordination can aggravate the cascading outages as well as hidden relay failures. Therefore it is necessary to find the reliability indices for different coordination methods in order to choose the best relay coordination method.

Many studies have been conducted on hidden failures in protective relays and their impact on power system reliability [9-15]. In [12], the definitions of 'vulnerability' and 'reliability of protection system' were provided to characterize numerically the impact of hidden protection failures on power system reliability. A random search algorithm based on power system heuristics was given for fast rare-event simulation of consecutive relaying malfunctions in bulk power systems [12]. References [13] and [14] found the weakness and the weakest links of a real sample network by considering hidden failures and cascading outages.

The effects of hidden failures on reliability and security were considered by nonsequential Monte Carlo Simulation [10, 11]. The faults were considered to be cleared after a normal probability distribution model. The model of a currentcarrying component paired with its associated protection system was also used in [10] and [11].

There are two basic Monte Carlo approaches: sequential and non-sequential simulation techniques. The sequential simulation technique provides an opportunity to incorporate chronological factors. In this approach, reliability-index probability distributions can be calculated. The impact of failure-state transitions has been ignored in the non-sequential method [16].

In this paper, a new algorithm is proposed, based on sequential Monte Carlo simulation to calculate reliability indices for the results of three different overcurrent relay coordination methods. Also, the hidden failures of protection system have been taken into account. Then the SAIFI, ENS, CAIFI, and CAIDI reliability indices are calculated. The proposed algorithm can evaluate reliability and calculate the effects of different relay coordination method results on reliability indices. 


\section{THEORY OF THE EXISTING METHOD}

\subsection{Hidden failures}

The hidden failures remain undetected until they are uncovered by the occurrence of another event in the power system [17]. There are two major failure modes of a protection system: 'failure to operate' and 'undesired trip' [10]. The former means that when a fault occurs in a power system, the protection system refuses to operate to clear the fault. The latter refers either to spontaneous operation in the absence of a fault, or to a trip caused by faults outside the protection zone. When a protection system component is in these two states, its protection system is suffering from hidden failure mode, and causes malfunction. The undesired tripping of the relays may occur simultaneously during the relays' operating period. In an interconnected system, the occurrence of undesired tripping may cause some load outages. In order to model the hidden failures of lines and protection systems, a Markov chain has been introduced in [10]. In the Markov chain, both component and protection system states have been combined.

In an interconnected system, the relays of both sides of a line should trip to clear the fault on the line and isolate the fault from the other parts of the network. For the sequential simulation, the states of the relays on both sides of the fault should be determined. Also, the states of each protection system which senses the fault current should be detected. Therefore, to obtain a precise result it is necessary to separate the component and protection Markov chain for the sequential simulation.

\subsection{Relay coordination}

Overcurrent relays normally have current setting multipliers ranging from $50 \%$ to $200 \%$ in steps of $25 \%$, which is referred to as Plug Setting (PS) [18]. However, the variables of interest in the optimal coordination problem are the Time Setting Multipliers (TSMs). Researchers have described various optimization methods to find the directional overcurrent relay settings [1, 2, 5, 7, 18]. The results of the coordination methods may be different. The best relay coordination method should isolate the fault as soon as possible. Delays in relay operating times will increase the probabilities of undesired trips in the backup relays.

Figure 1 shows a sample network in which all of the lines have been protected by directional overcurrent relays. To find the relay operating times, a more common formula using five terms for the relay characteristics is used [7].

In the network of Figure 1, if a fault occurs on line 3, the best case is when both of the relays $R_{3}$ and $R_{10}$ trip in the shortest time. If one of them fails to operate, the backup relays should trip and isolate the fault. However, if the operation time of the main relay $R_{3}$ is rather long, the backup relay $R_{2}$ may have an undesired trip. In this case, bus number 3 would be out of service. If the relay $R_{3}$ fails to operate, relay $R_{2}$ should trip. So, if the $R_{2}$ setting is such that the operation time is rather long, the other relays in the network that have sensed the fault current may have undesired trips. 


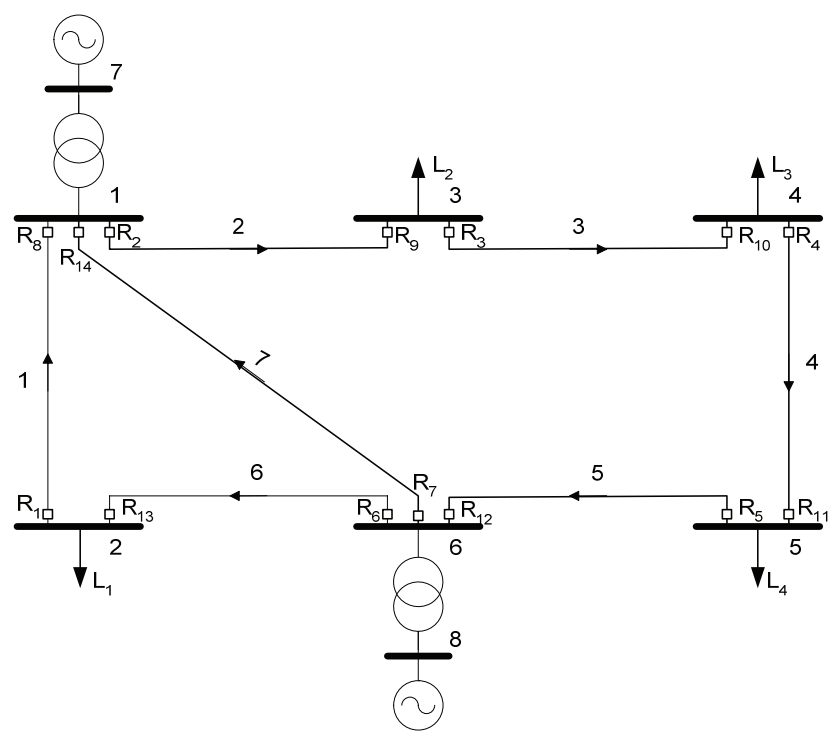

Figure 1: Sample case study (8-bus)

In the case where a three phase fault occurs at the middle of line 3 , the fault currents passing through the relays $R_{3}$ and $R_{10}$ are 2748.3 (A) and 1884.9 (A) respectively. The results of the dual simplex coordination method [2] show that if the main relay $R_{3}$ fails to operate, the backup relay $R_{2}$ will trip after 5.39 seconds. In this case, the backup relays of the relay $R_{3}$, such as $R_{1}, R_{6}$ and $R_{7}$, may have undesired trips. According to the results of the Genetic Algorithm coordination method [18], for a three phase fault at the middle of line 3 , the relay $R_{2}$ will trip after 0.88 seconds if the main relay $R_{3}$ fails to operate. In this case, the probabilities of undesired trips of the relays $R_{1}, R_{6}$, and $R_{7}$ are decreased. The same discussion can explain the backups of the relay $R_{10}$. In the case where the fault occurs on other lines of the network, similar results are achieved. So suitable relay coordination can reduce the incorrect trips of relays in the network, and increase the reliability of the system. Therefore, it is necessary to find a suitable coordination method by comparing the reliability indices of the results of different coordination methods.

\subsection{Reliability indices}

In this paper, the reliability indices SAIFI, ENS, CAIDI, and CAIFI are calculated for the results of different relay coordination methods by using sequential simulation. The indices' equations [19] are given below for easy access: 
SAIFI (System Average Interruption Frequency Index):

$S A I F I=\frac{\sum_{i} I_{i}}{N}$

where

$i$ is the $i^{\text {th }}$ year of the simulation;

$I_{i}$ is the number of the total buses interruptions in the $i^{\text {th }}$ year;

$\mathrm{N}$ is the number of simulation years.

CAIFI (Customer Average Interruption Frequency Index):

$\mathrm{CAIFI}_{j}=\frac{\sum_{i} l_{i}}{N}$

where

$i$ is the $i^{\text {th }}$ year of the simulation;

$I_{i}$ is the number of the $j^{\text {th }}$ bus interruptions in the $i^{\text {th }}$ year;

$\mathrm{N}$ is the number of simulation years.

CAIDI (Customer Average Interruption Duration Index):

$$
\text { CAIDI }_{j}=\frac{\sum_{i} t_{i}}{\sum_{i} n_{i}}
$$

where

$\mathrm{i}$ is the $\mathrm{i}^{\text {th }}$ year of the simulation;

$t_{i}$ is the sum of the $j^{\text {th }}$ bus interruption durations in the $i^{\text {th }}$ year;

$n_{i}$ is the number of the $j^{\text {th }}$ bus interruption in the $i^{\text {th }}$ year.

ENS (Total Energy Not Supplied Index):

$$
E N S=\frac{\sum_{i} E_{i}}{N}
$$

where

$i$ is the $i^{\text {th }}$ year of the simulation;

$E_{i}$ is the sum of the total energy not supplied in the $i^{\text {th }}$ year;

$\mathrm{N}$ is the number of simulation years.

\section{A NEW TECHNIQUE}

\subsection{Markov Chain}

In an interconnected system, both sides of a line are equipped with overcurrent relays. As mentioned in Section 2, to simulate the states of the relays of both sides of a component, it is necessary to separate the component Markov model and protection Markov model. Therefore, the next state of a relay in $t+\Delta t$ is determined by the probability of the transition from one state to another. In this 
paper, the proposed Markov models are similar to the model that is proposed in [10], but the protection and the component models are divided into two parts. In this paper, a component can be a line.

The Markov chains of the component and the protection system are shown in Figure 2 and Figure 3 respectively.

The states in Figure 2 are as below:

State 1: the line is up;

State 2: the line is down.

In Figure 2, the notations are as below:

$\lambda$ the failure rate of the line;

$\mu$ the repair rate of the line.

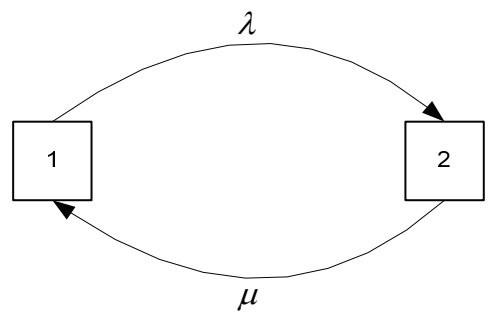

Figure 2: Markov model of a component

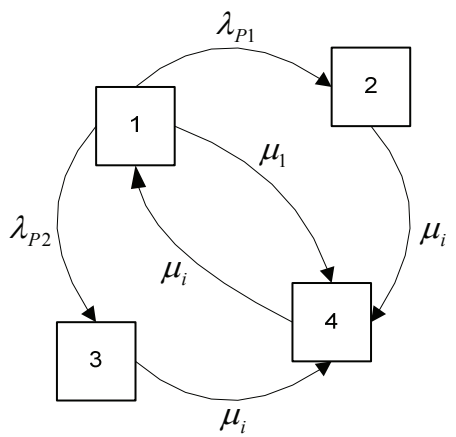

Figure 3: Protection system of Markov model

The states of Figure 3 are as below:

State 1: the protection system is up;

State 2: the protection system is under undesired trip condition;

State 3: the protection system is under failure to operate condition;

State 4: the protection system is being inspected. 
The notations in Figure 3 are as below:

$$
\begin{aligned}
& \mu_{i} \quad \text { the inspection rate of the protection system; } \\
& \mu_{I} \quad \text { the repair rate of the protection system; } \\
& \lambda_{P 1} \quad \text { the failure rate of the protection system owing to exposure to } \\
& \text { 'undesired trip'; } \\
& \lambda_{P 2} \text { the failure rate of the protection system owing to exposure to } \\
& \text { 'failure to operate'. }
\end{aligned}
$$

The protection failure probability is calculated from Figure 4 . In this figure, $P_{1}$ is the overcurrent protection failure probability. Also, $I_{3}$ and $I$ are, respectively, the overcurrent pickup setting and the current seen by the relay.

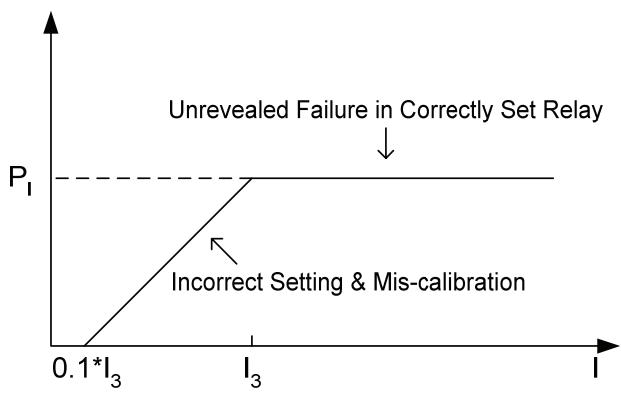

Figure 4: Overcurrent protection failure probability

\subsection{Coordination incorporation}

As mentioned in Section 2.2, the existing methods have considered only the hidden relay failures. Therefore, the relay coordination results have not been incorporated. According to the example, different relay coordination setting results will give different reliability evaluation results. To recognize how the results affect different load feeders, SAIFI, ENS, CAIFI, and CAIDI indices are calculated. The calculation of the indices from the current and the time settings of the relays used is described in section 4.2. Although the method with the minimum indices values is the most suitable coordination method, each relay coordination method has different reliability effects on different load feeders. This important evaluation is also done in this paper.

Because of ageing, some components of the network or protection devices may have different failure rates. In this case, the best coordination method results - those that possess the best reliability - are determined by incorporating the relay coordination result in the reliability evaluation. 


\subsection{Sequential Monte Carlo}

The sequential Monte Carlo simulation is implemented by dividing the simulation time period into small segments [20]. In this paper, the sequential simulation is applied for 3,000 years (as an example) for a good convergence of reliability indices. The steps of the simulation when no fault has occurred can be 1 hour. However, during a fault occurrence - because there is a need to obtain relays operating times - the steps of the simulation are changed to smaller time intervals. So the probabilities of the failure and repair rates should be changed. For example, the failure rate for a line is 10 per year. In other words, the failure rate will be $10 / 8,760$ per hour. In this case, the increment of the accuracy of the simulation is possible by reducing the time steps of the simulation. The transition rates of the Markov chain are calculated for any one of the simulation steps [21].

\subsection{Advantages of the new method in brief}

The advantages of the algorithm proposed in this paper are discussed briefly below:

1) In conventional relay coordination methods, only a minimization of the sum of the relay operating times is considered. However, by calculating the reliability index ENS, it is seen how the results of the relay coordination methods affect the interruption of different loads.

2) In existing reliability evaluation methods, hidden failures are taken into account, but the relay coordination results are not incorporated. In this paper, the results of relay coordination methods are also incorporated as well as the hidden failures of protection systems.

3) To obtain better accuracy, the sequential simulation is used instead of the nonsequential method.

4) To have sequential simulation, the Markov chain is improved by separating protection and component Markov models for the requirements of the algorithm.

\section{SIMULATION ALGORITHM}

\subsection{Assumptions}

1) 'Failure to operate' and 'undesired trip' of the protection system failures do not overlap.

2) Only the first order initial contingencies are considered.

3) All the failures are mutually independent.

4) The effects of the line overloads are ignored.

\subsection{Algorithm of the simulation}

To simulate the proposed algorithm, the sequential Monte Carlo technique is used. It is assumed that the time intervals during the fault are 100 milliseconds, and that the other time intervals are 1 hour. The steps of the algorithm are described below. 
Step 1: Find the first relay settings results (TSM and PS) using the first coordination program.

Step 2: Find the initial state of each protection device from Figure 3.

Step 3: If a fault occurs on a line go to Step 6.

Step 4: Increase simulation timer by 1 hour.

Step 5: Find the new states of the relays with respect to Figure 3 and the state transition matrix. Then go to Step 3.

Step 6: The fault current and the operating times of all the relays are calculated. The example of the roles of the relay operating times has been described in Section $2-2$.

Step 7: If the fault is cleared, calculate $E_{i}, l_{i}, t_{i}$ and $n_{i}$ parameters used in equations (1)-(4) and then go to Step 11.

Step 8: Increase the simulation timer and the fault timer by 100 milliseconds, and find the new states of the relays by using Figure 3 and related transition probabilities, which are described in Section 2-3.

Step 9: If a relay is in the 'undesired trip' state, the relay is considered to be a tripped relay according to Figure 4.

Step 10: If the fault timer is greater than the operating time of a relay and the relay is not in the 'failure to operate' state, the relay is considered to be a tripped relay. Go to Step 14.

Step 11: Increase the simulation timer by 1 hour and determine the new topology of the network.

Step 12: Save the outage load numbers and the outage duration of each load.

Step 13: By considering the repair rate of the line, check if the line is repaired or not.

Step 14: Compare the time of the simulation with year 3,000 ( $\mathrm{N}$ parameter has been taken to be 3,000). If it is less than 3,000 years, go to Step 3; if not, calculate the reliability indices using $\mathrm{I}_{\mathrm{i}}, \mathrm{n}_{\mathrm{i}}, \mathrm{E}_{\mathrm{i}}$ and $\mathrm{t}_{\mathrm{i}}$ which have been calculated in Step 7 , and go to the end of the coordination method results. If all coordination method results have not been considered, select the results of the next coordination method and go to Step 2.

\section{CASE STUDY}

\subsection{Test system and data}

The case study system (Figure 1) consists of 8 buses, 7 lines, 2 generators, 2 transformers, and 14 directional overcurrent relays. The network data, including the 
information of the lines, the transformers, and the generators, has been shown [22]. Table 1 shows the results of three different coordination methods. All of the relays are assumed to be normal inverse overcurrent type of Co-9 relays manufactured by Westinghouse. The first coordination method results, which are shown by $\mathrm{TSM}_{1}$, have been used with no objective function [2]. The relay models are non-linear Sachdev models. The second coordination results, shown by $\mathrm{TSM}_{2}$ in the third column of Table 1, are obtained by the dual simplex optimization method, and the relay models are linear Sachdev models [2]. The fourth column of Table 1 shows the results of the genetic algorithm optimization method. The relay models used in this method are also the linear Sachdev model. Table 2 shows the load numbers and the load buses data.

\begin{tabular}{|cccc|} 
Relay No. & TSM1 & TSM2 & TSM3 \\
\hline 1 & 1.4629 & 1.9528 & 0.05 \\
\hline 2 & 1.2654 & 1.7165 & 0.1 \\
\hline 3 & 1.5425 & 2.1384 & 0.05 \\
\hline 4 & 0.932 & 1.3311 & 0.05 \\
\hline 5 & 0.9581 & 1.4235 & 0.05 \\
\hline 6 & 1.1327 & 1.4662 & 0.15 \\
\hline 7 & 1.3143 & 2.8499 & 0.1 \\
\hline 8 & 0.9628 & 2.3744 & 0.15 \\
\hline 9 & 0.5568 & 0.8926 & 0.05 \\
\hline 10 & 0.5879 & 0.8759 & 0.1 \\
11 & 0.7342 & 1.2145 & 0.15 \\
12 & 1.1258 & 1.017 & 0.25 \\
13 & 1.1931 & 2.2711 & 0.05 \\
\hline 14 & 0.6674 & 1.4982 & 0.1 \\
\hline
\end{tabular}

Table 1: Protection system data

\begin{tabular}{|ccc|}
\hline Load No. & Bus & $\mathbf{P}(\mathbf{M W})$ \\
\hline 1 & 2 & 20 \\
\hline 2 & 3 & 30 \\
3 & 4 & 35 \\
4 & 5 & 25 \\
\hline
\end{tabular}

Table 2: Load data

Table 3 shows the failure and repair rates of each line. The protection system failure and repair rates are listed in Table 4. It is assumed that all of the lines have the same failure and repair rates. A similar assumption is considered for the protection systems. 


$\begin{array}{cc}\lambda & \mu \\ (1 / \text { year }) & (1 / \text { year }) \\ 10 & 150\end{array}$

Table 3: The lines failure and repair rates

$\begin{array}{cccc}\lambda \mathrm{p} 1 & \lambda \mathrm{p} 2 & \mu \mathrm{i} & \mu \mathrm{l} \\ (1 / \text { year }) & (1 / \text { year }) & (1 / \text { year }) & (1 / \text { hour }) \\ 0.08 & 0.4 & 4 & 0.25\end{array}$

Table 4: The protection systems transition rates

\subsection{Simulation results}

Based on the proposed algorithm, a computer code has been developed in MATLAB. By applying the algorithm to the results of the three coordination methods of Table 1 , reliability indices have been calculated. The variation of ENS and SAIFI indices in 3,000 years are illustrated in Figure 5 and Figure 6.

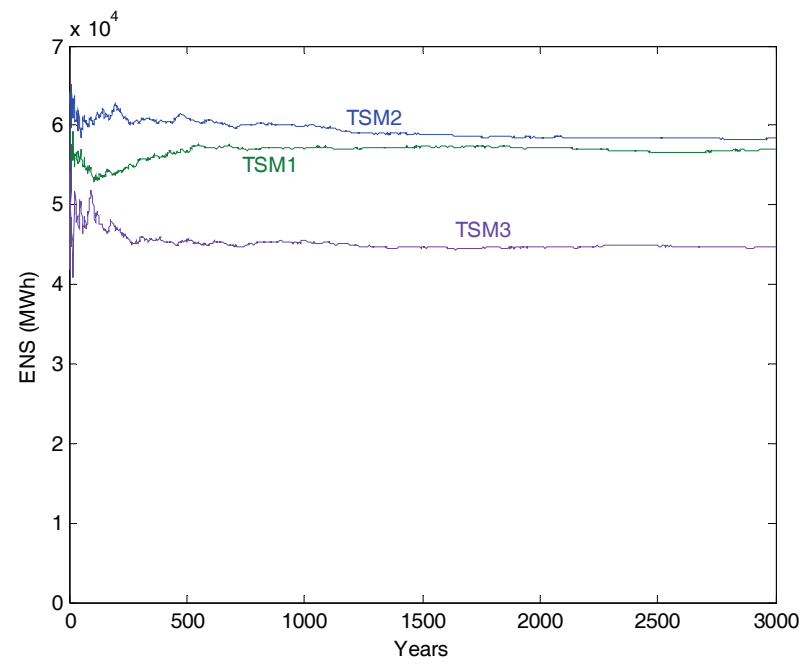

Figure 5: ENS for three coordination methods 


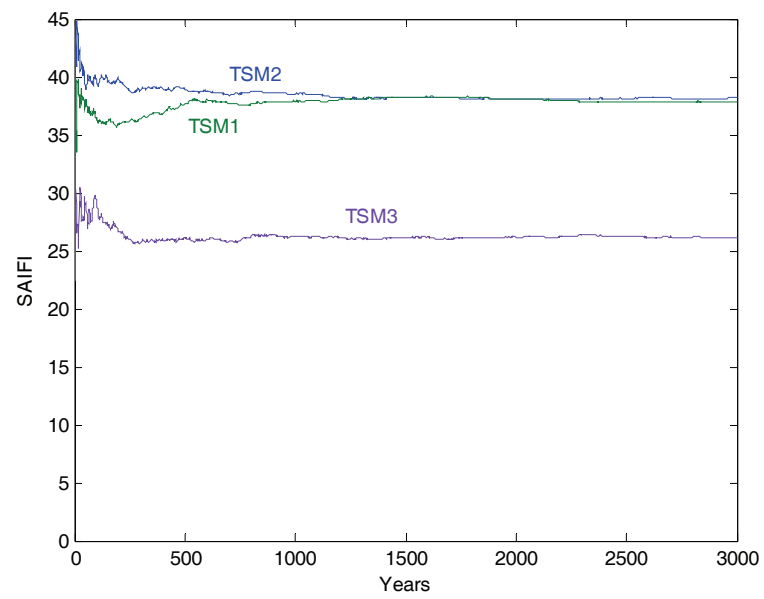

Figure 6: SAIFI for three coordination methods

The results of Figure 5 and Figure 6 show that the first method has $5.7 \times 10^{4} \mathrm{MWh}$ energy not supplied in the simulation duration, the second method has $5.84 \times 10^{4}$ $\mathrm{MWh}$ energy not supplied, and the third has $4.46 \times 10^{4} \mathrm{MWh}$ energy not supplied. Also, the SAIFI index in the first method is 37.874 , in the second method 38.193 , and in the third method 26.147. In other words, the SAIFI and ENS of the third coordination method are better than those of the first and second methods. The indices show that the first method is slightly better than the second, but the third coordination method is the best.

Table 5 includes CAIDI and CAIFI indices for the load buses, obtained using equations (2) and (3) and the developed algorithm of Section 4. In this table, Column 1 indicates the coordination methods and Column 2 shows the load numbers. In Columns 3 and 4, the values of CAIDI in hours and CAIFI specifying the load average interruption frequency are shown. According to the CAIDI index, the values of the index for the three coordination methods are almost the same. This is because the index is related to the repair rate of the components. However, the CAIFI index of the genetic algorithm optimization method (the third method) is better than the other methods - except in the case of load 3. The index shows that the first coordination method is best for load 3; but for the other loads the third method has a lower value for the CAIDI index.

According to the CAIFI index, the value of the index of load 1 for the first, second, and third coordination methods are $14.071,8.915$, and 4.897 respectively. In other words, the third method for this load number is two times better than the second method, and three times better than the first method. The above discussion shows that the genetic algorithm coordination method is better than the other coordination methods. The advantages of the first and second coordination methods relate only to load number 3 with respect to Table 5 . 


\begin{tabular}{cccc} 
Coordination Methods & Load No. & CAIDI & CAIFI \\
\hline \multirow{2}{*}{ TSM1 } & 1 & 58.66 & 14.071 \\
& 2 & 59.04 & 10.206 \\
& 3 & 59.01 & 4.12 \\
\hline \multirow{2}{*}{ TSM2 } & 4 & 58.55 & 9.477 \\
& 1 & 58.19 & 8.915 \\
& 2 & 58.72 & 9.715 \\
& 3 & 58.45 & 4.179 \\
& 4 & 58.03 & 15.383 \\
TSM3 & 1 & 58.31 & 4.897 \\
& 2 & 58.4 & 5.068 \\
& 3 & 58.19 & 11.206 \\
& 4 & 58.11 & 4.976
\end{tabular}

Table 5: Reliability indices of the load buses for the results of three different coordination methods

\section{CONCLUSION}

Based on a sequential Monte Carlo simulation, an algorithm is proposed that compares the results of three different coordination methods. In the proposed technique, the reliability indices have been calculated using the results of the three relay coordination methods. In the algorithm, both hidden failures and coordination method results have been taken into account. This algorithm has been applied to a sample network for the results of the method without an objective function, the dual simplex, and the genetic algorithm relay coordination methods. The results show that the genetic algorithm method is better than the other methods in the case study network.

\section{REFERENCES}

[1] Birla, D., Maheshwari, R. P., Om Gupta, H. 2005. Time-overcurrent relay coordination: A review', International Journal of Emerging Electric Power Systems, 2 (2).

[2] Askarian Abyaneh, H., Al-Dabbagh, M., Kazemi Karegar, H., Sadeghi, S. H. H., Jabbar Khan, R. A. 2003. A new optimal approach for coordination of overcurrent relays in interconnected power systems, IEEE Transactions on Power Delivery, 18 (2).

[3] Gan, Z., Elangovan, S., Liew, A. C. 1996. Microcontroller based overcurrent relay and directional overcurrent relay with ground fault protection, Electric Power Systems Research, 38, pp. 11-17. 
[4] Zeineldin, H., El-Saadany, E. F., Salama, M. A. 2005. Optimal coordination of directional overcurrent relay coordination', IEEE Power Engineering Society General Meeting.

[5] So, C. W., Li, K. K. 2000. Time coordination method for power system protection by evolutionary algorithm, IEEE Transactions on Industry Applications, 36 (5), pp. 1235-1240.

[6] So, C. W., Li, K. K. 2004. Intelligent method for protection coordination, IEEE International Conference of Electric Utility Deregulation Restructuring and Power Technology, Hong Kong.

[7] Kazemi Karegar, H., Askarian Abyaneh, H., Ohis, V., Meshkin, M. 2005. Pre-processing of the optimal coordination of overcurrent relays, Electric Power Systems Research, 75 (2-3), pp. 134-141.

[8] Billinton, R., Fotuhi-Firuzabad, M., Sidhu, T. S. 2002. Determination of the optimum routine test and self-checking intervals in protective relaying using a reliability model, IEEE Transactions on Power Systems, 17 (3).

[9] Phadke, A. G., Thorp, J. S. 1996. Expose hidden failures to prevent cascading outages, IEEE Computer Application in Power, 9 (3), pp. 20-23.

[10] Yu, X., Singh, C. 2002. Power system reliability analysis considering protection failures, IEEE Power Engineering Society Summer Meeting, 2, pp. 963-968.

[11] Yu, X., Singh, C. 2004. A practical approach for integrated power system vulnerability analysis with protection failures, IEEE Transactions on Power Systems, 19 (4), pp. 1811-1820.

[12] Wang, H., Thorp, J. S. 2001. Optimal location for protection system enhancement: A simulation of cascading outages, IEEE Transactions on Power Delivery, 16, pp. 528-533.

[13] Bae, K., Thorp, J. S. 1999. A stochastic study of hidden failures in power system protection, Decision Support Systems, 24 (3-4), pp. 259-268.

[14] Bae, K. Thorp, J. S. 1998. An importance sampling application: 179 Bus WSCC system under voltage based hidden failures and relay misoperation, Proceedings of the Thirty-First Hawaii International Conference on System Sciences, 3, pp. 39-46.

[15] Meeuwsen, J. J., Kling, W. L. 1997. The influence of protective relay schemes on the reliability indices of load points in meshed operated MV networks, $14^{\text {th }}$ International Conference and Exhibition on Electricity Distribution, CIRED 97.

[16] Billinton, R., Wangdee, W. 2005. Impact of utilising sequential and nonsequential simulation techniques in bulk-electric-system reliability assessment, IEE Proceedings, Generation, Transmission and Distribution, $152(5)$. 
[17] Elizondo, D. C., de la Ree, J., Phadke, A. G., Horowitz, S. 2001. Hidden failure in protection systems and their impact on wide-area disturbances, IEEE Power Engineering Society Winter Meeting, 2, pp. 710-714.

[18] Razavi, F., Askarian Abyaneha, H., Al-Dabbagh, M., Mohammadi, R., Torkaman, H. 2008. A new comprehensive genetic algorithm method for optimal overcurrent relays coordination, Electric Power Systems Research, 78 (4), pp. 713-720.

[19] Billinton, R., Allan, R. N. 1984. Reliability evaluation of power systems, New York, Plenum Press.

[20] Brown, R. E. 2002. Electric power distribution reliability, New York, Marcel Dekker.

[21] Singh, C., Billinton, R. 1977. System reliability modeling \& evaluation, London, U.K.; Hutchinson Publishing Group.

[22] Zeineldin, H. H., El-Saadany, E. F., Salama, M. M. A. 2006. Optimal coordination of overcurrent relays using a modified particle swarm optimization, Electric Power System Research, 76 (11), pp. 988-995. 